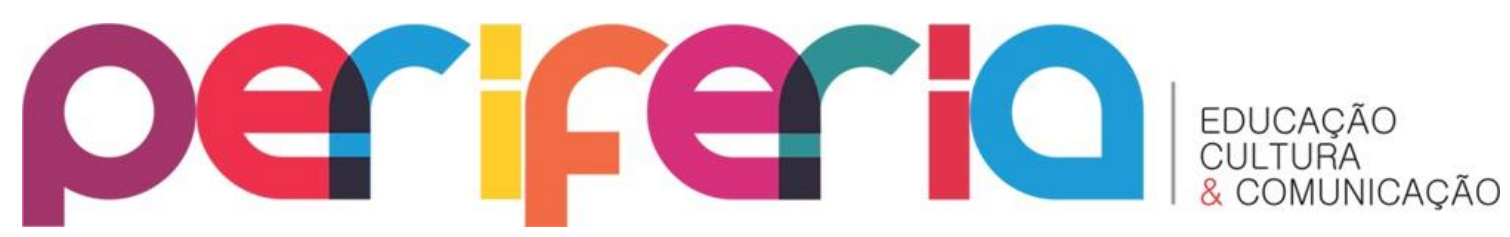

\title{
CULTURA AFRO-BRASILEIRA NA BAIXADA FLUMINENSE: PESQUISA E ENSINO
}

Eliana Laurentino ${ }^{1}$

Secretaria de Estado de Educação do Rio de Janeiro

\section{RESUMO}

$\mathrm{O}$ artigo propõe pensar as referências sócio-históricas como um lugar de pesquisa e ensino nas escolas da rede pública da Baixada Fluminense, a partir do curso "Patrimônio, Memória e Cultura Afro-brasileira na Baixada Fluminense". Por meio de um breve levantamento bibliográfico, foi possível observar que atualmente há uma grande quantidade de livros, dissertações e teses sobre a História da África e do negro no Brasil. Destaca-se que, nas últimas décadas, um movimento acadêmico sobre a temática da Baixada Fluminense gerou significativa produção historiográfica sobre a região. Entretanto, percebe-se que os avanços historiográficos repercutiram de forma limitada fora dos circuitos de especialistas e que isso tem impactado na produção de material didático e, consequentemente, na simplificação dos debates.

Palavras-chave: Pesquisa; ensino; patrimônio; cultura afro-brasileira; Baixada Fluminense.

\section{AFRO BRAZILIAN CULTURE IN THE BAIXADA FLUMINENSE: RESEARCH AND TEACHING ABSTRACT}

The article intends to think on the socio historical references as a place of research and teaching in the public schools of the Baixada Fluminense, regarding the Program on Patrimony, Memory and Afro Brazilian Culture in Baixada Fluminense. I identified several books, thesis and dissertations regarding the history of Africa and the black in Brazil, emphasizing that in recent decades an academic movement on the issue of Baixada Fluminense generated significant historical production about the region. It can be seen, however, that the historiographical advances have affected to a limited extent outside the circuits of experts and this has impacted the production of teaching resources and, consequently, simplifying the discussions.

Keywords: Research; teaching; patrimony; afro Brazilian culture; Baixada Fluminense.

\footnotetext{
${ }^{1}$ Professora da Secretaria de Estado de Educação do Rio de Janeiro e bolsista Faperj - TCT - Treinamento e Capacitação Técnica. Membro do Grupo de Pesquisa A cor da Baixada, Casa da Pesquisadora/Feuduc. E-mail: eliana2silva@yahoo.com.br.
} 


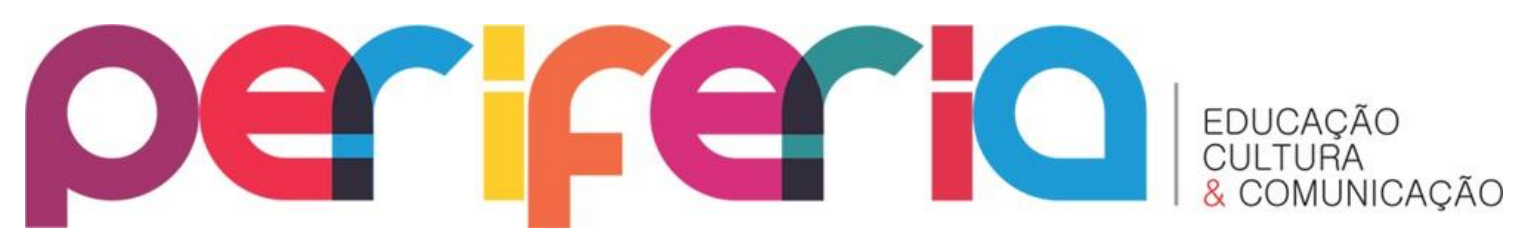

\section{INTRODUÇÃO}

Memória e patrimônio são temas de relevância para os diferentes sujeitos e seus significados na sociedade. Na Baixada Fluminense, o patrimônio cultural e a memória são temas contraditórios do ponto de vista das políticas públicas, uma vez que se encontram completamente envolvidos por descaso e abandono. Contudo, no campo da pesquisa que propõe um diálogo entre a Educação e a História, o patrimônio e a memória têm sido importantes campos de inserção de militantes de movimentos sociais e de professores das redes públicas de ensino, no sentido de desenvolver um sentimento de pertença e de identidades sociais entre os moradores da Baixada Fluminense.

Patrimônio, memória e cultura afro-brasileira são temáticas que bem representam essa a complexidade na Baixada Fluminense, uma vez que se trata de uma região com ampla maioria de negros e pardos que não contam com qualquer iniciativa pública, tanto no âmbito local, regional e nacional voltada para essa especificidade da população. Entretanto, ao longo das últimas duas décadas, os estudos sobre escravidão, diáspora africana, cultura afro-brasileira e a condição do negro na Baixada Fluminense têm se multiplicado como temas de projetos de pesquisa, extensão e pedagógicos em diferentes instituições da região. Assim, este artigo propõe pensar as referências sóciohistóricas como lugar de pesquisa e ensino nas escolas da rede pública da Baixada Fluminense, a partir do Curso de Formação Continuada sobre Patrimônio, Memória e Cultura Afro-brasileira na Baixada Fluminense.

A presença africana na região marca as transformações da sociedade brasileira ao longo do tempo. Ignorar essas sobrevivências é desprover a historiografia e as demais produções e reflexões sociais de suas origens, que podem favorecer a explicação de diferentes questões que persistem ao longo do tempo. As identificações dessas características implicam forte mecanismo de preservar a cultura, podendo oferecer importante contribuição não apenas para a história da região, mas para o diálogo com outros campos do conhecimento, como a história nacional, a história atlântica e a história da África. Essas ideias são fundamentais para estabelecer os 


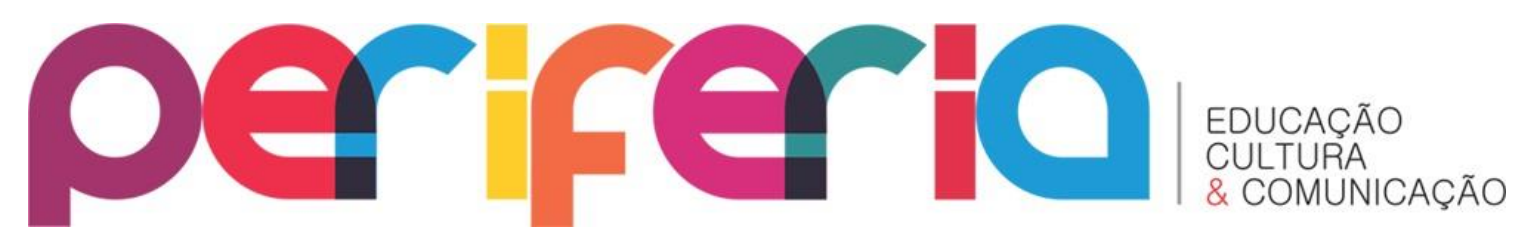

critérios de patrimônio cultural da Baixada Fluminense, considerando a diáspora africana e a cultura afro-brasileira.

Para pensar as referências sócio-históricas como lugar de pesquisa e ensino nas escolas da rede pública da Baixada Fluminense é necessário acompanhar as transformações e as continuidades das relações sociais na região. Uma iniciativa que pode ser destacada nesse sentido é o curso Patrimônio, Memória e Cultura Afrobrasileira na Baixada Fluminense. Tal curso está em andamento; conta com o apoio de diferentes instituições e com o financiamento da Fundação de Apoio à Pesquisa do Estado do Rio de Janeiro - Faperj ${ }^{2}$-; nele os alunos participam de atividades promovidas com material de apoio, disponibilidade de transportes para os estudos de campo e acesso ao que há de referência sobre o assunto, por meio de mesa de debates com professores convidados de diferentes instituições.

Foi possível identificar a produção historiográfica sobre a temática História da África e História do negro no Brasil, destacando alguns importantes estudos, em especial os trabalhos relacionados à Baixada Fluminense. Assim, cabe acompanhar um balanço historiográfico, visto que atualmente há grande quantidade de livros, dissertações e teses sobre a História da África e do negro no Brasil. Nas últimas décadas, um movimento acadêmico sobre a temática da Baixada Fluminense gerou significativa produção historiográfica sobre a região (ABREU, 2011; BEZERRA, 2008; BEZERRA, 2011; DEMETRIO, 2008; e GOMES, 1992, entre outros), especialmente, na ênfase sobre essa temática.

Importantes trabalhos, dentre eles, lançaram luz sobre as relações que envolviam diferentes interesses no mundo atlântico, revelando dimensões até então desconhecidas ou ignoradas pela historiografia. Para exemplificar, lembramos que, por muito tempo, os historiadores acreditavam que o tabaco era produzido na Bahia, quase exclusivamente, e enviado para regiões africanas. Do mesmo modo, que as relações entre o Rio de Janeiro e os portos afro-centro-ocidentais eram baseadas no

\footnotetext{
${ }^{2}$ Edital FAPERJ no 34/2013 - Programa Apoio à Melhoria do Ensino em Escolas da Rede Pública Sediadas no Estado do Rio de Janeiro, 2013. Coordenação do professor doutor Nielson Rosa Bezerra.
} 


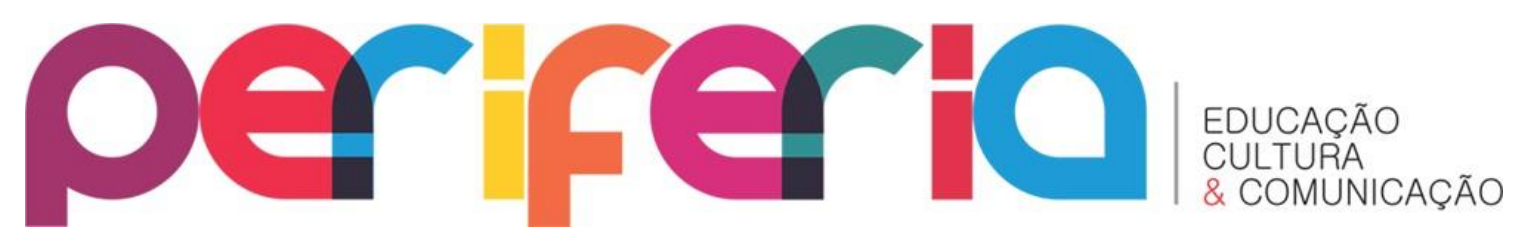

açúcar. Somente nas últimas décadas é que a produção historiográfica tem apontado para uma maior diversidade econômica nas relações, tendo como exemplo a cachaça. Recentes pesquisas têm apontado uma mercadoria brasileira, a farinha de mandioca, que segundo Mariza Soares (2009) foi um produto menosprezado pela historiografia e pelos proprietários de terras do período colonial.

Nielson Rosa Bezerra, em seu livro Escravidão, farinha e comércio no Recôncavo do Rio de Janeiro, afirma que esses interesses no mundo atlântico eram muito mais complexos do que se poderia imaginar e que a cidade do Rio de Janeiro concentrava a produção, consumo e distribuição da farinha de mandioca pelos mercados atlânticos. Seu trabalho chama a atenção para a concentração de pequenas e médias propriedades no Recôncavo da Guanabara no final do século XVIII com modesta produção de açúcar e aguardente, mas com expressiva produção de alimentos, sobretudo farinha de mandioca. Esta assegurava a inserção da região nos quadros da economia atlântica pela relação com o tráfico africano de escravos, além de permitir a mobilidade social do escravo (BEZERRA, 2011).

No tocante à mobilidade social, podemos destacar o estudo de Flávio Gomes sobre os quilombos da província do Rio de Janeiro, em especial aqueles situados na região de Iguaçu. Observando a formação dessas comunidades e a sobrevivência dos mocambos, o autor destaca o quanto a região do Recôncavo da Guanabara era privilegiada, sendo cortada por inúmeros rios que facilitavam o escoamento da produção e que também possibilitavam a manutenção dos quilombos. Pela rede de solidariedade que se constituía e com a conivência formada pelos escravos remadores, libertos, donos de embarcações e taberneiros que mantinham relações comerciais baseadas na lenha de mangue, os mocambos da região eram considerados praticamente indestrutíveis (GOMES, 1992).

Esses distintos trabalhos só confirmam que atualmente a questão não é a falta de material sobre o tema ou a ausência de estudos que destacam as contribuições, ações, relações e resistências da população negra durante a escravidão e no PósAbolição. Essa produção historiográfica demonstra como a região não estava isolada e 


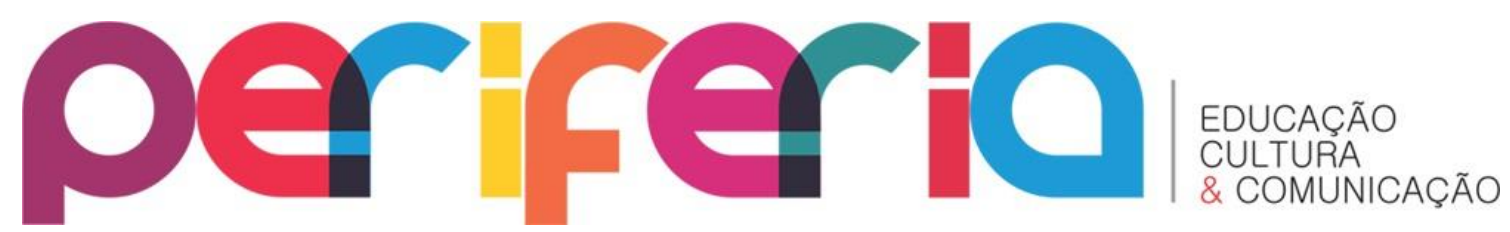

mantinha fortes conexões não apenas com o Rio de Janeiro, mas também com outras regiões do Brasil Colônia/Império e com a própria África. Entretanto, percebe-se que os avanços historiográficos repercutiram de forma limitada fora dos circuitos de especialistas e que isso tem impactado a produção de material didático e, consequentemente, a simplificação dos debates.

Minha vivência no curso de formação continuada permite apresentar algumas experiências que exemplificam as percepções obtidas sobre a relação entre a teoria e prática. Como método, realizei um levantamento das fichas de cadastro dos alunos participantes destacando alguns dados quantitativos, como volume de participantes, sexo, local de moradia e situação ocupacional. Juntamente com esses dados, realizei observação e acompanhamento das aulas; dos estudos de campo; dos debates em mesas-redondas, com um olhar qualitativo para as experiências desses alunos e seus possíveis desdobramentos na prática escolar. A proposta é, através dos jogos de escala, observar o micro via curso de formação continuada e sua relevância para contemplar a dimensão macro da prática de ensino nas escolas da Baixada Fluminense e a relação entre pesquisa e ensino (REVEL, 1998).

Hoje as questões são: como romper as barreiras entre a academia e a sala de aula? Como relacionar pesquisa e o ensino? Como despertar no professor a vivência de pesquisador que é inerente a seu ofício e que o faz não mero reprodutor, mas construtor de história? A escola básica não deve ser encarada como uma instância inferior no processo de produção de conhecimento, sobretudo em relação às universidades. A ideia de hierarquia se contrapõe a uma perspectiva de educação transformadora. Desse modo, o professor não deve abandonar os conhecimentos sistematizados da disciplina; deve ser alguém comprometido também com a produção do conhecimento. Ser um mediador na relação ativa do aluno, comprometendo-se com o que ensina.

A partir dessas questões, torna-se urgente refletir que, após mais de dez anos da promulgação da Lei no 10.369/2003, que torna obrigatório o ensino de História da África e Cultura Afro-brasileira nos diferentes segmentos da educação, ainda é possível 


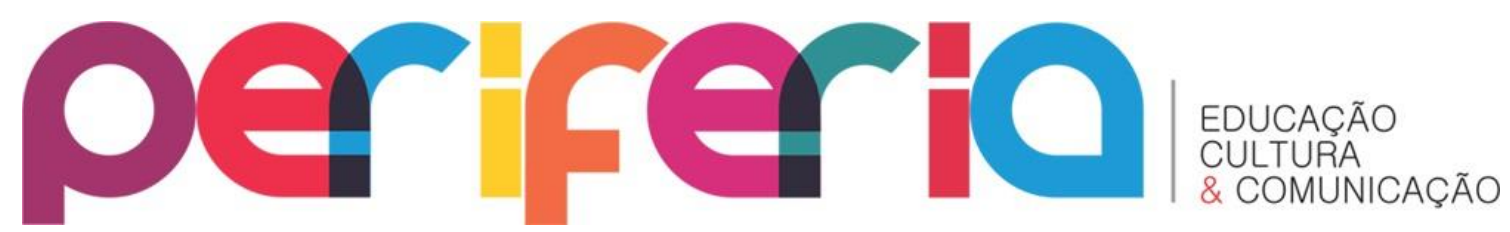

perceber a real necessidade de iniciativas que promovam sua efetiva implementação. Assim, destaco o artigo "Identidade nacional e ensino de História: a diversidade como patrimônio sociocultural", de Rebeca Gontijo (2003). Nesse trabalho, ela informa que nos Parâmetros Curriculares Nacionais (PCN), texto aprovado pelo MEC em 1996 que tem por objetivo uma tentativa de intervenção na organização do Ensino Fundamental no Brasil, a criticada visão do Brasil como produto da união de três raças não está ausente, mas disfarçada. Os PCN na década de 1990 permanecem com esse discurso ao apresentar "povos indígenas", "sociedades europeias" e "continente africano". Ou seja, os indígenas são povos, os europeus são sociedades e os africanos são algo marcado apenas por limites territoriais.

Ainda é possível identificar a entrevista de Monica Lima, importante pesquisadora sobre ensino de história da África, concedida à Revista História Hoje ${ }^{3}$. Quando indagada sobre o que recomendaria aos professores de História para a implementação da Lei e das Diretrizes, ela não deixa dúvida sobre a importância de ver a História da África além da escravidão atlântica e das relações com o Brasil escravista. Segundo Lima, esse exercício também deve ser realizado com os alunos com o objetivo de "ampliar o olhar no tempo e no espaço", evitando as generalizações, as simplificações e as idealizações.

Hebe Maria Mattos (2003), em seu artigo “O ensino de História e a luta contra a discriminação racial no Brasil" também alerta para as simplificações em livros didáticos, especialmente na ênfase na História da África, que, segundo a autora, precisa de um esforço pedagógico que rompa com a abordagem eurocêntrica que ainda ocorre nos programas de ensino da História nas escolas. A autora parte da série "História temática", que talvez seja o primeiro conjunto de livros didáticos que se propõe a adotar a proposta dos PCN.

Apesar de ser uma coleção bem atualizada com as discussões historiográficas, a coletânea apresenta a dificuldade de tratar as questões da pluralidade cultural e da

\footnotetext{
${ }^{3}$ Revista História Hoje, Anpuh, v. 1 no 1, p.131-136. jun. 2012. Entrevista a Martha Abreu e Silvio de Almeida Carvalho e Filho.
} 


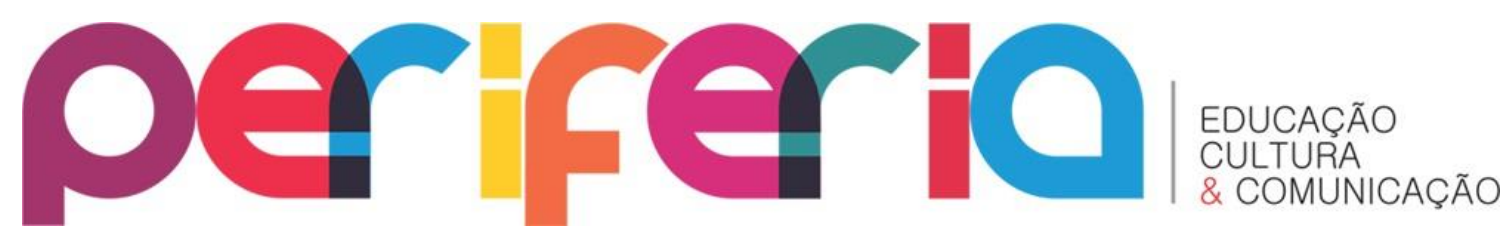

identidade negra em seus volumes. Destaque para a primeira unidade do livro Os mitos e as Grandes Navegações, em que a colonização permanece na maior parte do texto como uma empresa europeia na qual a África aparece apenas como uma sucessão de pontos geográficos a serem ultrapassados.

Outro destaque são os conteúdos da quarta unidade que são relevantes para a compreensão da questão racial no Brasil e o mundo contemporâneo, mas na qual as conexões históricas entre África, escravidão e a questão racial contemporânea mostram-se bastante problemáticas. Primeiro, os autores optaram por abordar a questão em dois capítulos que aparecem desvinculados da análise de conjunto da sociedade colonial. Depois, procedem quase que naturalmente com a associação entre africanos e escravidão, o que permite associar a questão racial como justificativa da escravidão desde o século XVI, e aborda o apartheid na África do Sul em um capitulo que discute a resistência escrava.

Os demais volumes apresentam problemas semelhantes. A Abolição da Escravidão é abordada apenas no tema que trata de "terra e propriedade". No livro dedicado ao tema "o mundo dos cidadãos", nem uma palavra é mencionada sobre escravidão, racismo e direitos civis. Se a proposta dos PCN é ultrapassar a valorização da diversidade, de modo a garantir o exercício de uma cidadania plena e não apenas o reconhecimento das diferenças, é possível perceber que o resultado está distante da proposta.

Assim, o que percebo como professora de História da rede estadual de ensino na Cidade do Rio de Janeiro é a manutenção desses discursos no material didático presente nas salas de aula. Torna-se urgente uma abordagem da História da África no mesmo nível de profundidade com que estudamos a História da Europa e suas influências sobre o continente americano. Percebo que meus pares compartilham esse desejo e que almejam mudanças na prática escolar, especialmente na Baixada Fluminense, cujos agentes ainda estão à margem dos estudos intelectuais e da mídia "positiva"4 .

\footnotetext{
4 Também por outra lente, foi possível observar como o estudo da África e da vida no negro no Brasil ainda precisa de investimentos para sua efetiva implementação. Assim, peço licença para registrar uma experiência particular, mas pertinente para exemplificar essa realidade nas escolas. Recentemente participei de uma atividade na escola da minha filha, aluna da Educação Infantil de uma escola modelo
} 


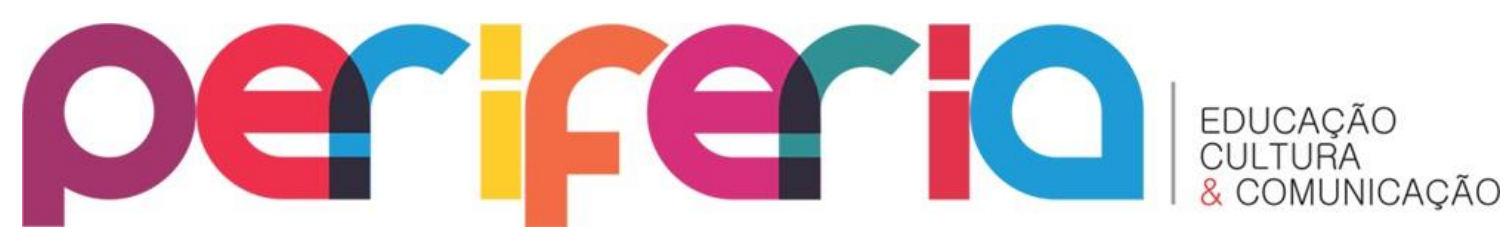

Nesse contexto, o curso de formação continuada, que recebeu 90 inscritos, se apresenta como oportuno para promover a formação e aperfeiçoamento, em especial de professores da Educação Básica, bem como estudantes de graduação, pósgraduação e normalistas com foco na valorização do Patrimônio, Memória e Cultura Afro-brasileira na Baixada Fluminense. Assim, não é por acaso que recebeu elevado número de inscritos (140 reservaram suas vagas e em torno de 100 pessoas se inscreveram efetivamente), o que representa a urgência de debates na região. Esse alto índice de procura do curso e a valorização de diferentes instituições e representações do movimento negro na Baixada Fluminense reforçam que é preciso estabelecer uma conexão próxima e permanente entre ensino de História e pesquisa.

Como aluna/observadora e envolvida com a estrutura administrativa e intelectual do curso, posso sinalizar algumas impressões importantes. O curso tinha como proposta inicial contemplar 50 alunos, mas recebeu mais de 100 inscrições de diferentes áreas profissionais. Além de professores da rede estadual e de diferentes municípios, outros profissionais se interessaram pelo curso: militares; mestres de capoeira; administradores e produtores culturais, entre outros.

\begin{tabular}{|c|c|c|}
\hline \multicolumn{3}{|c|}{ Situação funcional } \\
\hline & Quantidade & $\%$ \\
\hline Estudantes & 31 & 34 \\
\hline Professores & 34 & 37 \\
\hline Outros & 24 & 26 \\
\hline Não identificados & 1 & 1 \\
\hline Total & 90 & \\
\hline
\end{tabular}

Fonte: Ficha de inscrição realizada pelos alunos ${ }^{5}$

da rede municipal de ensino do Rio de Janeiro. A proposta era muito interessante: tratava-se de uma peça de fantoche sobre "A formação do povo brasileiro"; o objetivo seria que os pais realizassem a encenação. Rapidamente, como pretensa mãe participativa da vida escolar de minha pequena, lá fui eu, e fiquei surpresa que, no texto produzido pelas professoras sobre a "formação da sociedade brasileira", o negro tinha apenas uma fala, e era no momento em que chegava ao Brasil como mão de obra. Após o meu questionamento e da mãe que escolheu esse personagem, mas que reclamou por receber pouca participação, a professora realizou uma releitura e buscou mais informações para enriquecer o diálogo. Então, percebi que não é a falta de material ou mesmo de conhecimento, mas de prática de ensino que faz com que os estudos fiquem simplificados.

${ }^{5}$ Sobre os números de alunos, cabe uma explicação: quando divulgado, o curso recebeu procura de 140 pessoas. Entre essas, 100 pessoas estiveram na primeira aula. Contudo, apenas 90 pessoas preencheram a ficha, efetivando suas inscrições. 


\section{periferio}

A influência africana está na base da maioria das nossas manifestações populares, como a capoeira e o samba, entre outros. Por sua face material, identificam-se construções que remetem a um passado escravo, como senzala, fazendas, igrejas, estradas. Mas também há outras construções que são referência de um tempo mais recente, como a sede de escolas de samba e blocos carnavalescos, casas de parteiras, escolas fundadas no período do Pós-Abolição, casas de santo, entre outras. Da mesma forma, é possível identificar as heranças da cultura bantu e nagô na interface imaterial do patrimônio cultural da região, como os rituais de candomblé e umbanda, as tradições populares como as folias de reis, os sambas e as cantigas populares, entre outras referências. Não é por acaso que, além de estudantes de História e professores, também contamos com a presença de mestres de capoeira como frequentadores assíduos do curso. Essas distintas atividades profissionais fortalecem o sentimento de que a população da região está direta ou indiretamente envolvida com atividades no cotidiano relacionadas à cultura afro-brasileira e que almejam entender mais sobre suas referências sócio-históricas. Assim, esse trabalho caminha para um acompanhamento direto aos distintos interesses que compõem esse mosaico de alunos com atividades profissionais distintas.

Também é relevante que, dentre as mais de 100 pessoas que realizaram registro para participar do curso na página do grupo na internet, 90 alunos efetuaram inscrição; desse grupo, 52\% são mulheres e $84 \%$ moradores da Baixada Fluminense, como segue na tabulação abaixo.

\begin{tabular}{|l|l|l|}
\hline \multicolumn{3}{|c|}{ Alunos inscritos } \\
\hline & Quantidade & $\%$ \\
\hline Mulheres & 47 & 52 \\
\hline Homens & 33 & 36 \\
\hline Não Identificados* & 10 & 11 \\
\hline Total & 90 & \\
\hline
\end{tabular}

Fonte: Ficha de inscrição realizada pelos alunos 


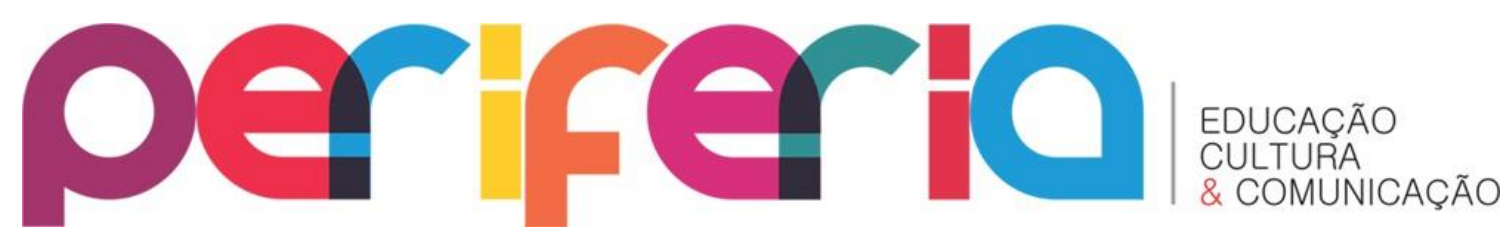

Esses números são representativos para entendermos que não é por acaso que a Baixada Fluminense, que se caracteriza pelos altos índices de afrodescendentes na formação de sua população em geral, deseja conhecer suas referências históricas como forma de valorização de sua cultura e de sua construção histórica. O maior índice feminino está intimamente relacionado à participação das mulheres na prática docente e à busca feminina de participação e atuação ativa na sociedade.

\begin{tabular}{|c|c|c|}
\hline \multicolumn{3}{|l|}{ Local de moradia } \\
\hline & Quantidade & $\%$ \\
\hline Baixada Fluminense & 76 & 84 \\
\hline Rio de Janeiro & 9 & 10 \\
\hline Outros & 3 & 3 \\
\hline Não Identificados & 2 & 2 \\
\hline
\end{tabular}

Fonte: Ficha de inscrição realizada pelos alunos

O interesse ficou evidenciado pela permanência dos alunos até o final, bem como pela contínua procura por participação, mesmo como ouvintes, especialmente nos estudos de campo. Um exemplo desse interesse aparece na participação significativa dos alunos no estudo de campo "Entre a vida e a morte dos escravos na cidade do Rio de Janeiro", que ocorreu no dia 26 de maio, em um dia especialmente chuvoso, mas que contou com um número expressivo de alunos. É possível evidenciar que a Baixada Fluminense é um campo rico para a prática do ensino e da pesquisa. Esse curso tem sido um exemplo de que é possível promover inúmeros multiplicadores e de que são necessários diálogos nos espaços culturais da região com o objetivo de gerar produtos que poderão promover o desenvolvimento cultural desses espaços e das pessoas.

Assim, considero necessária e urgente uma reflexão e uma ação potente sobre a produção de materiais gerados a partir do curso e a contribuição para a prática docente. Vejo como ganho do curso fazer com que ele não se esgote nos encontros promovidos e que os alunos/professores participantes do curso sejam reais 


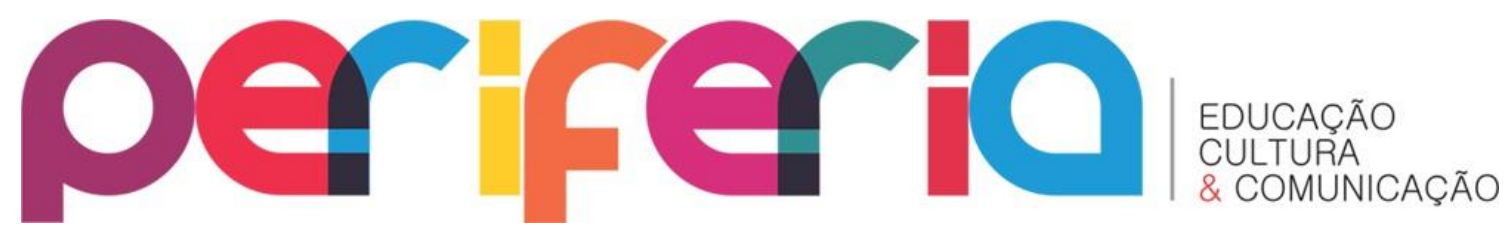

multiplicadores. Observei que essa é uma das metas do curso, pois se propõe a continuar com os alunos a produção de diferentes materiais. Entre eles inventários interativos, mediante estudos individuais que contemplem diferentes interesses; também é proposto o roteiro didático-pedagógico, que permite a construção do conhecimento histórico da região e a produção do memorial de Joãozinho da Gomeia.

Nesse sentido, o Curso de Formação Continuada sobre Patrimônio, Memória e Cultura Afro-brasileira na Baixada Fluminense objetiva, por meio do investimento pessoal do organizador, professor Nielson Rosa Bezerra, realizar a produção de um busto do Joãozinho da Gomeia. Esse projeto pretende revitalizar o local onde era o terreiro desse ícone e ao mesmo tempo comemorar essa data significativa não só para a população duque-caxiense, mas para todos os brasileiros. No ano do centenário de Joãozinho da Gomeia, que estabeleceu residência em Duque de Caixas e se tornou o pai de santo mais conhecido do Brasil, pouco se falou sobre esse assunto na região - e menos ainda nas escolas. Sobre esse importante líder religioso já existem produções historiográficas (GAMA, 2014; MENDES, 2014; PERALTA, 2000), e isso também sinaliza para a necessidade de debates sobre o assunto para que o preconceito não seja alimentado pela ignorância. A Baixada Fluminense, a partir da década de 1970, passou a ser a região com maior concentração de terreiros do Rio de Janeiro. Os estudos e os esforços didáticos sobre essas temáticas são ferramenta fundamental para o debate sobre a violência contra os membros dessas manifestações culturais e a falta do direito à liberdade religiosa (FONSECA, 2006).

Tudo isso confirma que a proposta é que o curso não se esgote em si, mas que seja uma ação contínua de atuação e produção de materiais. Dessa forma, considero que a Baixada Fluminense é um terreno fértil para a íntima relação entre pesquisa e ensino. $E$, mesmo com mais de 20 trabalhos, entre livros, dissertações de mestrado e teses de doutorado sobre a escravidão e a Pós-Abolição na região, ainda é preciso um envolvimento maior entre a academia e as escolas. A Lei $n$ ㅇ 10.639/2003 permitiu um avanço na busca do conhecimento do continente africano e suas tradições, mas ainda 


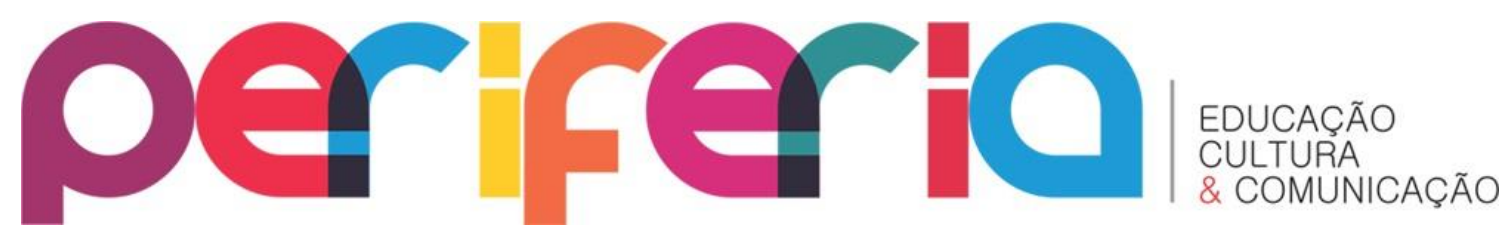

é preciso investir para que a efetiva implementação ocorra nas escolas e na sociedade; sinto que estamos no caminho.

\section{REFERÊNCIAS}

ABREU, Maurício de Almeida. Geografia histórica do Rio de Janeiro (1502-1700). Vol. 2. Rio de Janeiro: Andreia Jakobson, 2011.

BEZERRA, Nielson Rosa. As chaves da liberdade: confluências da escravidão no Recôncavo do Rio de Janeiro (1833-1888). Niterói: EdUFF, 2008.

BEZERRA, Nielson Rosa. Escravidão, farinha e comércio no Recôncavo do Rio de Janeiro, século XIX. Duque de Caxias: APPH-CLIO, 2011.

CANDAU, Vera Maria. Pluralismo cultural, cotidiano escolar e formação de professores. In: CANDAU, Vera Maria (org.). Magistério: construção cotidiana. Petrópolis: Vozes, 1997.

CHAGAS, M. S.; ABREU, R. (orgs.). Memória e patrimônio: ensaios contemporâneos. Vol. 1. Rio de Janeiro: DP\&A, 2003.

CHUVA, Márcia (org.). A invenção do patrimônio. Vol. 1. Rio de Janeiro: MinC/IPHAN, 1995.

DEMÉTRIO, Denise Vieira. Famílias escravas no Recôncavo da Guanabara: séculos XVII e XVIII. 2008. Dissertação (Mestrado). Universidade Federal Fluminense. Niterói, 2008.

DIAS, Amália. Entre laranjas e letras: processos de escolarização no distrito-sede de Nova Iguaçu (1916-1950). Tese (Doutorado). Universidade Federal Fluminense. Niterói, 2012.

FONSECA, Denise Pini Rosalem. Presença do axé: mapeando terreiro no Rio de Janeiro. Rio de Janeiro: Pallas, 2006.

FREYRE, Gilberto Freyre. Casa grande e senzala: formação da família patriarcal sob o regime de economia patriarcal. Rio de Janeiro: Maia \& Schimit, 1933.

GAMA, Elizabeth Castelano. Mulato, homossexual e macumbeiro: que rei é este? Trajetória de João da Gomeia (1914-1971). Duque de Caxias: APPH-CLIO, 2014. (Série Recôncavo da Guanabara, vol. 2.).

GOMES, Flávio dos Santos. História de quilombolas: mocambos e comunidades de senzalas no Rio de Janeiro - século XIX. 1992. Dissertação (Mestrado). Universidade Estadual de Campinas. Campinas, 1992.

GONTIJO, Rebeca. Identidade nacional e ensino de história: a diversidade como 'Patrimônio sociocultural'. In: ABREU, Martha; SOIHET, Rachel (orgs). Ensino de História: conceitos, temáticas e metodologias. Rio de Janeiro: Casa da Palavra, 2003.

HALL, Stuart. Da diáspora: identidades e mediações culturais. Belo Horizonte: EdUFMG, 2006.

LE GOFF, Jacques. História e memória. Campinas: Editora da Unicamp, 2003. LOVEJOY, Paul. Identity in the Shadow of Slavery. New York: Continuum, 2000. 


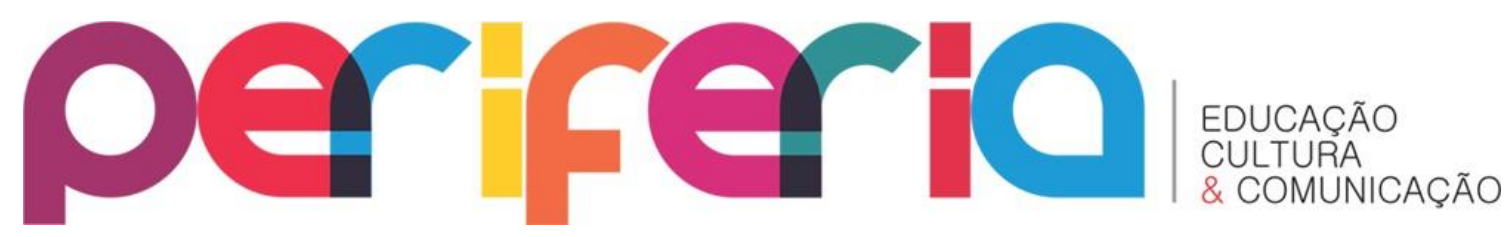

MATTOS, Hebe Maria. O ensino de História e a luta contra a discriminação racial no Brasil. In: ABREU, Martha; SOIHET, Rachel (orgs.). Ensino de História: conceitos, temáticas e metodologias. Rio de Janeiro: Casa da Palavra, 2003.

MENDES, Andrea. Vestidos de realeza: fios e nós centro-africanos no candomblé de Joãozinho da Gomeia. Duque de Caxias: APPH-CLIO, 2014. (Série Recôncavo da Guanabara, vol. 1).

PERALTA, Antônio Carlos Lopes. Um vento de fogo - João da Gomeia: um homem em tempo. 2000. Dissertação (Mestrado). Programa de Mestrado em História, Universidade Severino Sombra, Vassouras, 2000.

REVEL, J. (org.). Jogos de escala: a experiência da microanálise. Rio de Janeiro: FGV, 1998.

SOARES, Mariza de Carvalho. Engenho sim, de açúcar não: o engenho de farinha de Frans Post. Varia História, Belo Horizonte, v. 25, no 41, p. 61-83, jan./jun. 2009.

SOARES, Mariza de Carvalho; BEZERRA, Nielson Rosa (orgs.). Escravidão africana no Recôncavo da Guanabara, séculos XVII-XIX. Niterói: EdUFF, 2011. 